\title{
Antihyperglycemic, antihyperlipidemic, anti-inflammatory and adenosine deaminase- lowering effects of garlic in patients with type 2 diabetes mellitus with obesity
}

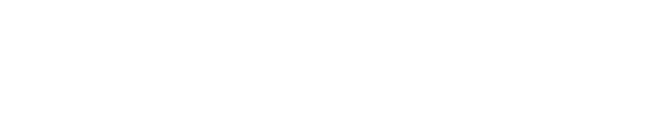

\author{
Rahat Kumar' \\ Simran Chhatwal' \\ Sahiba Arora ${ }^{2}$ \\ Sita Sharma ${ }^{3}$ \\ Jaswinder Singh' \\ Narinder Singh' \\ Vikram Bhandari' \\ Ashok Khurana ${ }^{4}$ \\ 'Department of Pharmacology, \\ ${ }^{2}$ Department of Biochemistry, \\ ${ }^{3}$ Department of Obstetrics and \\ Gynecology, ${ }^{4}$ Department of Medicine, \\ Sri Guru Ram Das Institute of Medical \\ Sciences and Research, Amritsar, India
}

Introduction: Type 2 diabetes mellitus is a chronic disorder characterized by chronic hyperglycemia, with long term macrovascular and microvascular complications. The treatment is lifestyle management, exercise, weight control, and antihyperglycemic drugs such as sulfonylureas, biguanides, alpha-glucosidase inhibitors, thiazolidinediones, and meglitinide. Recently, a direct association between high levels of C-reactive protein and serum adenosine deaminase levels in patients with uncontrolled diabetes with long-term complications has been seen. This study was conducted to assess the antihyperglycemic, lipid-lowering, anti-inflammatory, and improving glycemic control of garlic in type 2 diabetes patients with obesity.

Materials and methods: This was an open-label, prospective, comparative study, conducted on 60 patients having type 2 diabetes mellitus and obesity. The patients were divided into two groups of 30 each, of either sex. Group 1 was given metformin tablets, $500 \mathrm{mg}$ twice a day (BD)/three times a day (TDS), after meals, and group 2 was given metformin tablets, $500 \mathrm{mg}$ $\mathrm{BD} / \mathrm{TDS}$, after meals, along with garlic (Allium sativum) capsules, $250 \mathrm{mg}$ BD. Patients were routinely investigated for fasting and postprandial blood glucose, glycosylated hemoglobin $\left(\mathrm{HbA}_{1 \mathrm{c}}\right)$, serum adenosine deaminase levels and lipid profile (serum cholesterol, high-density lipoprotein cholesterol, triglycerides and low-density lipoprotein cholesterol) at the start of the study. Patients were followed up for 12 weeks, with monitoring of fasting and postprandial blood glucose at 2 week intervals, and monitoring of the other parameters at the end of study. Data obtained at the end of the study was statistically analyzed using Student's $t$ test.

Results: It was observed that both metformin alone and metformin with garlic reduced fasting blood glucose and postprandial blood glucose significantly, with a greater percentage reduction with metformin plus garlic; however, change in $\mathrm{HbA}_{1 \mathrm{c}}$ levels was not significant. A fall in total cholesterol, triglyceride, and low-density lipoprotein and an increase in high-density lipoprotein were more pronounced in patients treated with metformin plus garlic. Similarly, a fall in C-reactive protein and adenosine deaminase levels was greater in patients taking metformin with garlic than in patients taking only metformin.

Conclusion: Garlic has been shown to have antihyperglycemic and lipid-lowering properties. The additional lowering of C-reactive protein and serum adenosine deaminase levels with garlic suggests that garlic can be a valuable agent in providing good glycemic control and the prevention of long-term complications.

Keywords: C-reactive protein, metformin, Allium sativum

\section{Introduction}

Diabetes mellitus is a metabolic disorder of multiple etiologies, characterized by chronic hyperglycemia and long-term complications. ${ }^{1}$ The overall prevalence of
E-block, Ranjit Avenue, Amritsar,

Punjab, India 14300I

Tel +91 9876125136

Email rahat_sharma66@yahoo.com
(C) 2013 Kumar et al, publisher and licensee Dove Medical Press Ltd. This is an Open Access article which permits unrestricted noncommercial use, provided the original work is properly cited. 
diabetes mellitus in the global population is approximately $6 \%$, of which $90 \%$ is type 2 diabetes. India had 32 million diabetics in 2000, and this number is expected to increase to 80 million by $2030 .{ }^{2,3}$ Characteristic symptoms are polydipsia, polyuria, blurring of vision, and weight loss; in its most severe form, symptoms are ketoacidosis, nonketotic hyperosmolar coma, and death. The principle laboratory findings of type 2 diabetes mellitus is hyperglycemia, either fasting blood glucose (FBG) level $>126 \mathrm{mg} / \mathrm{dL}$ or glycosylated hemoglobin $\left(\mathrm{HbA}_{1 \mathrm{c}}\right)>6.5 \% .{ }^{4}$ In patients with type 2 diabetes, previous prospective studies have shown an association between the degree of hyperglycemia and increased risk of microvascular complications, sensory neuropathy, myocardial infarction, stroke, macrovascular mortality, and all-cause mortality. ${ }^{5} \mathrm{C}$-reactive protein (CRP) is a main inflammatory factor that is produced by the liver during acute infection or inflammation, and its concentration in plasma can increase as much as 1000-fold during injury and infection. CRP levels are increased in endothelial dysfunction and atherogenesis, and increased levels have been associated with macrovascular disease and the nonocular microvascular complications of type 2 diabetes. ${ }^{6-8} \mathrm{CRP}$ is a predictor of early atherosclerotic damage and is related to high adiposity (mainly abdominal), insulin resistance, and dyslipidemia. ${ }^{9} \mathrm{CRP}$ directly impairs nitric oxide production, resulting in endothelial dysfunction. In the Atherosclerosis Risk in Communities (ARIC) study, ${ }^{10}$ there was a positive link found between systemic inflammation and the development of type 2 diabetes mellitus and cardiovascular complications. An increase in adenosine deaminase increased serum $(\mathrm{S})$ and tissue adenosine deaminase (ADA) activity is not well known. It is seen that, with higher ADA activity in insulin-sensitive tissues, glucose uptake into cells is reduced; ${ }^{12}$ thus, if ADA activity is suppressed, insulin sensitivity may be improved and cellular proliferation, inflammation, and T-cell activity (all of which are associated with the pathophysiology of insulin resistance) can be altered. The general consensus is that the main treatment of type 2 diabetes is lifestyle management, like exercise and weight reduction. Pharmacological agents, including sulfonylureas, biguanides, alpha-glucosidase inhibitors, thiazolidinediones, and meglitinide, are also used; however, long-term complications of type 2 diabetes mellitus are unaltered with these agents. ${ }^{13}$ Metformin is currently being used in type 2 diabetes as the first-choice oral agent, along with appropriate diet control and lifestyle advice. Metformin acts primarily by reducing the hepatic glucose output and improving insulin sensitivity in the liver and muscle. Metformin has pleiotropic vascular effects that act on endothelial imbalance, probably increasing nitric oxide bioavailability, decreasing atheroma plaque growth, improving the atherogenic lipid profile, and inhibiting lipid incorporation into vessel walls, thereby inhibiting vascular smooth muscle cell proliferation. ${ }^{14}$ The American Diabetic Association has recommended metformin as a first-line agent for the treatment of type 2 diabetes, as metformin helps in weight loss and lowers fasting plasma insulin concentrations, total and low-density lipoprotein cholesterol, and free fatty acids,${ }^{15}$ however, long-term complications are not altered with metformin therapy. Previous studies ${ }^{16,17}$ have shown mixed results of metformin therapy on CRP, but the studies of nondiabetic patients have reported greater inhibitory effects on CRP than the studies of diabetics. Thus, the effect of metformin therapy on CRP needs to be established in type 2 diabetic patients. The World Health Organization Expert Committee on diabetes has recommended that traditional medicinal herbs can be further investigated for the treatment of diabetes. ${ }^{18}$ The following are the most commonly used medicinal herbs: Allium sativum (garlic), Ginseng species, Momordica charantia (bitter melon), Trigonella foenum-graecum (fenugreek) and A. cepa (onion). Garlic has a reputation in particular because of its widespread health use around the world as a dietary as well as therapeutic supplement. Garlic contains a variety of effective compounds, such as allicin, a sulfur-containing compound that exhibits anticoagulant, antithrombotic, antioxidant, hypocholesterolemic, hypoglycemic, and hypotensive activities. ${ }^{19,20}$ The probable mechanism underlying garlic's hypoglycemic effects is increased insulin secretion and sensitivity. However, apart from its antihyperglycemic and lipid-lowering properties, garlic has been shown to have ADA-inhibiting activities in cultivated endothelial cells. ${ }^{21}$ Similarly, aged garlic extract has been shown to produce favorable effects on inflammatory markers and coronary atherosclerosis progression in diabetics with cardiovascular risk. ${ }^{22}$ However, to the authors' knowledge, there are no studies reporting the effect of garlic on CRP or other markers of inflammation in subjects treated with garlic; in vitro studies have shown only that high concentrations of garlic can decrease cytokine production in endothelial cells, suggesting anti-inflammatory properties. ${ }^{23}$ Aged garlic extract was shown to increase nitric oxide production and decrease the output of inflammatory cytokines from cultured cells in 15 men with coronary artery disease, ${ }^{24}$ hence the significance of investigating the effects of garlic on the markers of inflammation in addition to other markers is important. This study was planned to evaluate the antihyperglycemic, 
antihyperlipidemic, and CRP- and ADA-lowering effects of garlic in patients with diabetes mellitus and obesity.

\section{Materials and methods}

This was an open-label, prospective, randomized, comparative study conducted in type 2 diabetes mellitus patients with obesity. The patients visiting the Department of Medicine's outpatient clinic at Sri Guru Ram Das Charitable Hospital of the Sri Guru Ram Das Institute of Medical Sciences And Research, Amritsar, Punjab, India were enrolled in the study. A total of 60 patients of either male or female sex, fulfilling the inclusion and exclusion criteria (described below), were included in the study and were divided randomly into two groups of 30 each. The total duration of the study was 12 weeks. Group 1 was given metformin tablets (the control drug), $500 \mathrm{mg}$ twice a day (BD) or three times a day (TDS) after meals, as per each patient's blood glucose profile and drug tolerance. Group 2 was given garlic, one capsule BD after meals along with metformin (control) tablets, $500 \mathrm{mg}$ BD or TDS after meals, as per each patient's blood glucose profile and drug tolerance. The test drug garlic used was available under the brand name of Lasuna and was a $250 \mathrm{mg}$ capsule manufactured by The Himalaya Drug Company (Bangalore, India). The garlic dose administered in this study was chosen using information from the literature provided by The Himalaya Drug Company. ${ }^{25}$

Patients were followed up at 2-week intervals and were routinely investigated for FBG and postprandial blood glucose (PPBG), as described by the GOD-POD method (using glucose oxidase enzyme), ${ }^{26}$ at day 0 and at 2, 4, 6, 8, and 12 weeks. Additionally, at the beginning and end of the study, the following parameters were tested: $\mathrm{S}$ cholesterol $(\mathrm{CH})$, estimated by cholesterol oxidase-phenol-aminophenazone (CHOD-PAP) method; ${ }^{27}$ triglycerides (TG), using glycerolphosphate oxidase-phenol-aminophenazone (GPO-PAP) end point assay method; ${ }^{28}$ high-density lipoprotein cholesterol (HDL-C), by polyethylene glycol cholesterol oxidase-phenolaminophenazone (PEG-CHOD-PAP) method; ${ }^{29}$ low-density lipoprotein cholesterol (LDL-C), as described by Bairaktar et al; ${ }^{30} \mathrm{~S}$ high sensitivity CRP (hs-CRP), as described by Mendall et al; ${ }^{31} \mathrm{~S}$ ADA level, as described by Giusti and Galanti; ${ }^{32}$ $\mathrm{HbA}_{1 \mathrm{c}}$, analyzed by a Nycocard ${ }^{\circledR}$ Reader (Axis-Shield Diagnostics Ltd, Dundee, UK); ${ }^{33}$ and body mass index (BMI). ${ }^{34}$

The study was conducted in accordance with the principles of good clinical practices and the Declaration of Helsinki. The approval of the Sri Guru Ram Das Institute of Medical Sciences and Research ethics committee was obtained prior to the conduct of study. Written informed consent was obtained from all the patients, and all the risks and benefits were explained to patients in their own language. Patients were advised to undertake diet control and regular exercise as per the protocol designed by the World Health Organization, ${ }^{18}$ and to exclude dietary garlic intake.

\section{Inclusion criteria}

The inclusion criteria were male/female patients with type 2 diabetes, aged 40-65 years, with FBG $>126 \mathrm{mg} / \mathrm{dL}$, $\mathrm{HbA}_{1 \mathrm{c}}>6.5 \%$, and BMI $>25 \mathrm{~kg} / \mathrm{m}^{2}$.

\section{Exclusion criteria}

The following criteria were used to exclude patients from study: type 1 diabetes; past or present history of ketoacidosis; bleeding disorders; surgery in the preceding 6 weeks or anticipated surgery during the trial period; hypersensitivity to the test drug; any cardiovascular, hepatic, or renal disorder; other ailments, like congestive heart failure, tuberculosis, rheumatoid arthritis, and gout; and pregnancy. Candidates could be receiving long-term insulin therapy or any other antihyperglycemic agent apart from metformin.

\section{Statistics}

The data obtained were tabulated as mean \pm standard deviation (SD) and analyzed using Student's $t$-test. The level of significance was determined as its $P$ value with $P>0.05$ taken as not significant, $P<0.05$ taken as significant at the $5 \%$ significance level, $P<0.01$ taken as significant at the $1 \%$ significance level, and $P<0.001$ was taken as highly significant.

\section{Results}

The age of participants varied from 40-75 years. The mean age was $53.8 \pm 12.2$ and $52.8 \pm 11.0$ years in groups 1 and 2 , respectively, and this difference was statistically nonsignificant $(P>0.05)$.

In group 1, patients received metformin $500 \mathrm{mg}$ BD/TDS after meals for 12 weeks. The baseline FBG was $160.32 \pm 16.73 \mathrm{mg} / \mathrm{dL}$, which declined progressively and reached a nadir of $134.97 \pm 10.28 \mathrm{mg} / \mathrm{dL}$, and PPBS was $192.38 \pm 10.70 \mathrm{mg} / \mathrm{dL}$, which declined progressively and reached a nadir of $150.90 \pm 10.28 \mathrm{mg} / \mathrm{dL}$, at the end of 12 weeks.

In group 2, patients received garlic $250 \mathrm{mg} \mathrm{BD}$ along with metformin $500 \mathrm{mg} \mathrm{BD} / \mathrm{TDS}$ after meals for 12 weeks. The baseline FBG was $157.10 \pm 13.54 \mathrm{mg} / \mathrm{dL}$, which declined progressively and reached a nadir of $121.34 \pm 6.90 \mathrm{mg} / \mathrm{dL}$, and PPBG was $188.32 \pm 16.71 \mathrm{mg} / \mathrm{dL}$, which declined 
progressively and reached a nadir of $140.90 \pm 10.20 \mathrm{mg} / \mathrm{dL}$, at the end of 12 weeks. There was a statistically nonsignificant $(P>0.05)$ difference in FBG and PPBG in both the groups at the start of study; however, the mean fall in FBG and PPBG was highly significant $(P<0.001)$ in both groups, ie, group 1 on metformin and group 2 on garlic plus metformin, at the end of study when compared with start of treatment (Table 1). When group 2 was compared with group 1, there was a significant reduction $(P<0.01)$ for group 2 in FBG and PPBG after starting of treatment until the end of study (Table 2).

The results of various parameters in group 1 and group 2 are presented in Tables 3 and 4 . These results show that there was a nonsignificant difference $(P>0.05)$ in $\mathrm{HbA}_{1 \mathrm{c}}$, lipid profile (S CH, S TG, S HDL-C, S LDL-C), and S ADA levels, and BMI, between group 1 and group 2 at the start of study (Table 5).

The mean $\mathrm{HbA}_{1 \mathrm{c}}$ at the beginning of the study in group 1 was $7.67 \% \pm 0.97 \%$, and at the end of the study this decreased to $7.45 \% \pm 0.77 \%$. Similarly, in group 2, the mean $\mathrm{HbA}_{1 \mathrm{c}}$ level was $7.48 \% \pm 0.59 \%$ in the beginning and decreased to $7.05 \% \pm 0.50 \%$ at the end of 12 weeks. This mean fall in $\mathrm{HbA}_{1 \mathrm{c}}$ was not significant $(P>0.05)$ in both groups at the start and end of treatment (Tables 3 and 4). However, at the end of treatment, when group 2 was compared with group 1 , a significant $(P<0.05)$ fall in $\mathrm{HbA}_{1 \mathrm{c}}$ was observed in group 2 (Table 5).

For group 1, the values of various parameters of the lipid profile are presented in Table 3 . The total $\mathrm{S} \mathrm{CH}$ was $249.53 \pm 20.44 \mathrm{mg} / \mathrm{dL}$ at the start of study and $242.97 \pm 20.83 \mathrm{mg} / \mathrm{dL}$ at the end of 12 weeks. S TG at the start of study was $190.87 \pm 50.47 \mathrm{mg} / \mathrm{dL}$ and at the end of 12 weeks was $184.80 \pm 48.07 \mathrm{mg} / \mathrm{dL}$. S LDL-C at the start of study was $186.70 \pm 26.35 \mathrm{mg} / \mathrm{dL}$ and at the end of 12 weeks was $181.60 \pm 25.36 \mathrm{mg} / \mathrm{dL}$, and S HDL-C at the start of study was $41.90 \pm 7.65 \mathrm{mg} / \mathrm{dL}$ and at the end of 12 weeks was $43.93 \pm 7.32 \mathrm{mg} / \mathrm{dL}$. There was significant fall $(P<0.05)$ in $\mathrm{S}$ total $\mathrm{CH}, \mathrm{S}$ TG, and S LDL-C, with a significant increase
$(P<0.05)$ in S HDL-C, at the end of treatment in group 1. Similarly in group 2, the lipid profile was as follow: $\mathrm{S}$ total $\mathrm{CH}$ at the start of study was $254.07 \pm 16.03 \mathrm{mg} / \mathrm{dL}$ and at the end of 12 weeks was $238.50 \pm 19.49 \mathrm{mg} / \mathrm{dL} ; \mathrm{S}$ TG at the start of study was $182.60 \pm 6.44 \mathrm{mg} / \mathrm{dL}$ and at the end of 12 weeks was $170.47 \pm 17.10 \mathrm{mg} / \mathrm{dL}$; S LDL-C at the start of study was $188.33 \pm 36.46 \mathrm{mg} / \mathrm{dL}$ and at the end of 12 weeks was $178.77 \pm 34.39 \mathrm{mg} / \mathrm{dL}$, and S HDL-C at the start of study was $42.50 \pm 8.96 \mathrm{mg} / \mathrm{dL}$ and at the end of 12 weeks was $46.97 \pm 9.14 \mathrm{mg} / \mathrm{dL}$. There was significant fall $(P<0.01)$ in $\mathrm{S}$ total $\mathrm{CH}, \mathrm{S}$ TG, and S LDL-C, and a significant increase $(P<0.01)$ in S HDL-C, at the end of treatment in group 2 (Table 4 ). However, when group 2 was compared with group 1 at the end of treatment, it was observed that there was significant fall $(P<0.05)$ in $\mathrm{S}$ total $\mathrm{CH}, \mathrm{S}$ TG, and S LDL-C, and a significant increase $(P<0.01)$ in S HDL-C in group 2 as compared with group 1 (Table 5).

The $\mathrm{S}$ hs-CRP level in group 1 at the start of treatment was $1.29 \pm 1.79 \mathrm{mg} / \mathrm{dL}$ and at the end was $1.28 \pm 0.09 \mathrm{mg} / \mathrm{dL}$; there was no significant difference $(P>0.05)$ in $\mathrm{S}$ hs-CRP level in group 1 at the end of study when compared with the start of study (Table 3). Similarly, the S ADA level in group 2 at the start of treatment was $1.30 \pm 0.71 \mathrm{mg} / \mathrm{dL}$ and at the end was $1.25 \pm 0.17 \mathrm{mg} / \mathrm{dL}$; there was significant fall $(P<0.05)$ in S ADA level at the end of study when compared with the start of study in group 2 (Table 4). When levels of S ADA in group 2 were compared with those in group 1, there was a nonsignificant difference $(P>0.01)$ in $\mathrm{S}$ hs-CRP at the start of treatment but a significant fall $(P<0.05)$ in $\mathrm{S}$ hs-CRP levels in group 2 at the end of study (Table 5).

The S ADA level in group 1 at the start of treatment was $43.23 \pm 16.14 \mathrm{mg} / \mathrm{dL}$ and at the end of treatment was $41.48 \pm 12.26 \mathrm{mg} / \mathrm{dL}$; there was a nonsignificant fall $(P>0.05)$ in S ADA level at the end of study in group 1 , when compared with the start of study (Table 3). In group 2, S ADA level at the start of treatment was $44.62 \pm 18.34 \mathrm{mg} / \mathrm{dL}$ and at the end was $36.18 \pm 16.06 \mathrm{mg} / \mathrm{dL}$; there was a significant fall $(P<0.01)$ in S ADA level at the end of study

Table I Fasting and postprandial blood glucose levels in both groups at different time intervals

\begin{tabular}{lllllll}
\hline Group & Day 0 & Week 2 & Week 4 & Week 6 & Week 8 & Week I2 \\
\hline Group I & & & & & & \\
$\quad$ FBG & $160.32 \pm 16.73$ & $154.7 \pm 15.47^{* *}$ & $149.9 \pm 14.15^{* *}$ & $146.6 \pm 13.57^{* *}$ & $|40.8 \pm 11.9|^{* *}$ & $134.9 \pm 10.28^{* * *}$ \\
PPBG & $192.38 \pm 10.70$ & $173.7 \pm 15.40^{* *}$ & $160.9 \pm 14.18^{* *}$ & $156.6 \pm 13.53^{* *}$ & $154.8 \pm\left. 11.9\right|^{* *}$ & $150.9 \pm 10.28^{* * *}$ \\
Group 2 & & & & & \\
$\quad$ FBG & $157.10 \pm 13.54$ & $141.0 \pm 13.36^{* *}$ & $129.8 \pm 12.24^{* *}$ & $130.6 \pm 11.04^{* *}$ & $125.9 \pm 9.22^{* *}$ & $121.34 \pm 6.90^{* * *}$ \\
PPBG & $188.32 \pm 16.71$ & $164.74 \pm 15.43^{* *}$ & $151.9 \pm 14.10^{* *}$ & $145.6 \pm 13.54^{* *}$ & $144.8 \pm 11.98^{* *}$ & $140.9 \pm 10.20^{* * *}$ \\
\hline
\end{tabular}

Notes: Values are expressed as mean \pm standard deviation. $* * P<0.01$ (significant at I\% significance level); $* * * P<0.00 \mathrm{I}$ (highly significant).

Abbreviations: FBG, fasting blood glucose; PPBG, postprandial blood glucose. 
Table 2 Comparison of fasting and postprandial blood glucose levels in both groups at different time intervals

\begin{tabular}{|c|c|c|c|c|}
\hline \multirow[t]{2}{*}{ Duration } & \multicolumn{2}{|l|}{$\begin{array}{l}\text { FBG } \\
(\text { mean } \pm S D)\end{array}$} & \multicolumn{2}{|l|}{$\begin{array}{l}\text { PPBG } \\
(\text { mean } \pm \text { SD })\end{array}$} \\
\hline & Group I & Group II & Group I & Group II \\
\hline Day 0 & $160.32 \pm 16.73$ & $157.10 \pm 13.54^{\mathrm{NS}}$ & $192.38 \pm 10.70$ & $\left.|88.32 \pm| 6.7\right|^{\mathrm{Ns}}$ \\
\hline Week 2 & $154.7 \pm 15.47$ & $141.0 \pm 13.36 *$ & $173.7 \pm 15.40$ & $164.74 \pm 15.43^{*}$ \\
\hline Week 4 & $149.9 \pm 14.15$ & $129.8 \pm 12.24 * *$ & $160.9 \pm 14.18$ & $151.9 \pm 14.10^{* *}$ \\
\hline Week 6 & $146.6 \pm 13.57$ & $130.6 \pm 11.04 * *$ & $156.6 \pm 13.53$ & $145.6 \pm 13.54^{* *}$ \\
\hline Week 8 & $140.8 \pm 11.91$ & $125.9 \pm 9.22 * *$ & $|54.8 \pm 11.9|$ & $144.8 \pm 11.98^{* *}$ \\
\hline Week 12 & $134.9 \pm 10.28$ & $121.34 \pm 6.90 * *$ & $150.9 \pm 10.2$ & $140.9 \pm 10.20 * *$ \\
\hline
\end{tabular}

Notes: ${ }^{N S} P>0.05$ (not significant); $* P<0.05$ (significant at $5 \%$ significance level); $* * P<0.01$ (significant at $I \%$ significance level).

Abbreviations: FBG, fasting blood glucose; PPBG, postprandial blood glucose; SD, standard deviation.

in group 2 when compared with the start of study (Table 4). When level of S ADA in group 2 was compared to group 1, there was no significant difference $(P>0.05)$ at the start of treatment but a significant fall $(P<0.01)$ in S ADA level was seen in group 2 at the end of study (Table 5).

\section{Discussion}

The present study monitored the effects of garlic in comparison with the standard antidiabetic agent, metformin, on glycemic profile, lipid profile, $\mathrm{S}$ hs-CRP and S ADA levels, and BMI, in patients with type 2 diabetes mellitus and obesity.

\section{Glycemic profile}

It is well established in observational studies that the risk of microvascular and macrovascular complications is related to hyperglycemia, as measured by FBG, PPBG, and $\mathrm{HbA}_{1 \mathrm{c}} \cdot{ }^{34,35}$ Thus, the reduction of hyperglycemia in type 2 diabetic patient is of utmost importance. In our study, it was observed that with treatment of metformin alone and with metformin

Table 3 Results of various study parameters in group I

\begin{tabular}{lccl}
\hline Parameters & Day 0 & Week I2 & Change \\
\hline $\mathrm{HbA}_{\mathrm{Ic}}(\%)$ & $7.67 \pm 0.97$ & $7.45 \pm 0.77^{\mathrm{NS}}$ & $-2 \%$ \\
$\mathrm{BMI}\left(\mathrm{kg} / \mathrm{m}^{2}\right)$ & $27.23 \pm 2.77$ & $26.86 \pm 12.69^{\mathrm{Ns}}$ & $-1 \%$ \\
$\mathrm{~S}$ hs-CRP $(\mathrm{mg} / \mathrm{dL})$ & $1.29 \pm 1.79$ & $1.28 \pm 0.09^{\mathrm{NS}}$ & - \\
S ADA $(\mathrm{U} / \mathrm{L})$ & $43.23 \pm 16.14$ & $41.48 \pm 12.26^{\mathrm{NS}}$ & $-4 \%$ \\
Lipid profile $(\mathrm{mg} / \mathrm{dL})$ & & & \\
$\quad$ & & & \\
S total cholesterol & $249.53 \pm 20.44$ & $242.97 \pm 20.83^{*}$ & $-2 \%$ \\
S triglyceride & $190.87 \pm 50.47$ & $184.80 \pm 48.07^{*}$ & $-3 \%$ \\
S LDL-C & $186.70 \pm 26.35$ & $181.60 \pm 25.36^{*}$ & $-2 \%$ \\
S HDL-C & $41.90 \pm 7.65$ & $43.93 \pm 7.32^{*}$ & $+4 \%$
\end{tabular}

Notes: Values are expressed as mean \pm standard deviation. NsP $>0.05$ (not significant); $* P<0.05$ (significant at $5 \%$ significance level).

Abbreviations: $\mathrm{ADA}$, adenosine deaminase; $\mathrm{BMI}$, body mass index; $\mathrm{HbA}_{\mathrm{Ic}}$, glycosylated hemoglobin; HDL-C, high-density lipoprotein cholesterol; hs-CRP, high sensitivity C-reactive protein; LDL-C, low-density lipoprotein cholesterol; S, serum. plus garlic, there was significant reduction $(P<0.01)$ in FBG and PPBG (Table 1). However, this reduction was significantly higher $(P<0.01)$ in patients taking garlic along with metformin as compared with metformin alone (Table 2). Similarly, there was a nonsignificant $(P>0.05)$ reduction in $\mathrm{HbA}_{1 \mathrm{c}}$ in both the groups, but this reduction was higher $(P<0.05)$ in patients taking garlic along with metformin when compared with metformin alone.

Stumvoll et $\mathrm{al}^{36}$ conducted a study of metformin in ten patients that showed a highly significant decrease $(P<0.001)$ in FBG and $\mathrm{HbA}_{1 \mathrm{c}}$ at the end of study. Similarly, DeFronzo and Goodman ${ }^{37}$ showed reduction in the glycemic profile with metformin, in multicenter patient trials. These results were in conformity to the present study where a significant decrease $(P<0.001)$ in FBG and PPBG was observed with metformin and with garlic along with metformin. When group 2 was compared with group 1, it was observed that there was significant fall $(P<0.01)$ in FBG and PPBG in patients taking garlic along with metformin when compared with metformin alone (Table 2). Ashraf et al, ${ }^{38}$ in a 24 -week, single

Table 4 Results of various study parameters in group 2

\begin{tabular}{lccl}
\hline Parameter & Day 0 & Week I2 & Change \\
\hline $\mathrm{HbA}_{\mathrm{Ic}}(\%)$ & $7.40 \pm 0.59$ & $7.05 \pm 0.50^{\mathrm{NS}}$ & $-4 \%$ \\
$\mathrm{BMI}\left(\mathrm{kg} / \mathrm{m}^{2}\right)$ & $27.72 \pm 1.74$ & $25.97 \pm 10.70^{\mathrm{NS}}$ & $-6 \%$ \\
$\mathrm{~S}$ hs-CRP $(\mathrm{mg} / \mathrm{dL})$ & $1.30 \pm 0.7 \mathrm{I}$ & $1.25 \pm 0.17^{*}$ & $-3 \%$ \\
S ADA $(\mathrm{U} / \mathrm{L})$ & $45.62 \pm 18.34$ & $36.18 \pm 16.06^{* *}$ & $-20 \%$ \\
Lipid profile $(\mathrm{mg} / \mathrm{dL})$ & & & \\
$\quad$ S total cholesterol & $254.07 \pm 16.03$ & $238.50 \pm 19.49^{*}$ & $-6 \%$ \\
S triglyceride & $182.60 \pm 6.44$ & $170.47 \pm 7.17^{*}$ & $-6 \%$ \\
S LDL-C & $188.33 \pm 36.46$ & $178.77 \pm 34.39^{*}$ & $-5 \%$ \\
S HDL-C & $42.50 \pm 8.96$ & $46.97 \pm 9.14^{* *}$ & $+10 \%$ \\
\hline
\end{tabular}

Notes: Values are expressed as mean \pm standard deviation. Nsp $>0.05$ (not significant); $* P<0.05$ (significant at $5 \%$ significance level); $* * P<0.01$ (significant at I\% significance level).

Abbreviations: ADA, adenosine deaminase; $\mathrm{BMI}$, body mass index; $\mathrm{HbA}_{\mathrm{lc}}$, glycosylated hemoglobin; HDL-C, high-density lipoprotein cholesterol; hs-CRP, high sensitivity C-reactive protein; LDL-C, low-density lipoprotein cholesterol; S, serum. 
Table 5 Comparison of various parameters in both groups

\begin{tabular}{|c|c|c|c|c|}
\hline \multirow[t]{2}{*}{ Parameter } & \multicolumn{2}{|l|}{ Day 0} & \multicolumn{2}{|l|}{ Week I 2} \\
\hline & Group I & Group II & Group I & Group II \\
\hline $\mathrm{HbA}_{\mathrm{Ic}}(\%)$ & $7.67 \pm 0.90$ & $7.40 \pm 0.5^{\mathrm{Ns}}$ & $7.45 \pm 0.70$ & $7.05 \pm 0.5^{*}$ \\
\hline BMI $\left(\mathrm{kg} / \mathrm{m}^{2}\right)$ & $27.23 \pm 2.77$ & $27.72 \pm 1.74^{\mathrm{NS}}$ & $26.86 \pm 12.69$ & $25.97 \pm 10.70^{\mathrm{NS}}$ \\
\hline $\mathrm{S}$ hs-CRP (mg/dL) & $1.29 \pm 1.79$ & $\mathrm{I} .30 \pm 0.7 \mathrm{I}^{\mathrm{NS}}$ & $1.28 \pm 0.09$ & $1.25 \pm 0.17^{*}$ \\
\hline S ADA (U/L) & $43.23 \pm 16.14$ & $44.62 \pm 18.34^{\mathrm{NS}}$ & $42.40 \pm 12.26$ & 36. $18 \pm 16.06 * *$ \\
\hline \multicolumn{5}{|l|}{ Lipid profile (mg/dL) } \\
\hline S total cholesterol & $249.53 \pm 20.44$ & $254.07 \pm 16.03^{\mathrm{NS}}$ & $242.97 \pm 20.83$ & $231.50 \pm 19.49 *$ \\
\hline S triglyceride & $190.87 \pm 50.47$ & $185.60 \pm 6.44^{\mathrm{NS}}$ & $184.80 \pm 48.07$ & $170.47 \pm 17.10 *$ \\
\hline S LDL-C & $186.70 \pm 26.35$ & $188.33 \pm 36.46^{\mathrm{NS}}$ & $181.60 \pm 25.36$ & $170.77 \pm 34.39 *$ \\
\hline S HDL-C & $41.90 \pm 7.65$ & $42.50 \pm 8.96^{\mathrm{NS}}$ & $43.93 \pm 7.32$ & $47.97 \pm 9.14 * *$ \\
\hline
\end{tabular}

Notes: Values are expressed as mean \pm standard deviation. ${ }^{N S} P>0.05$ (not significant); ${ }^{P} P<0.05$ (significant at $5 \%$ significance level); ${ }^{* * P}<0.0 \mathrm{I}$ (significant at $I \%$ significance level).

Abbreviations: ADA, adenosine deaminase; BMI, body mass index; $\mathrm{HbA}_{1 \mathrm{c}}$, glycosylated hemoglobin; HDL-C, high-density lipoprotein cholesterol; hs-CRP, high sensitivity C-reactive protein; LDL-C, low-density lipoprotein cholesterol; S, serum.

blind, placebo-controlled study of 210 type 2 diabetes mellitus patients taking garlic treatment, showed a significant decrease $(P<0.005)$ in FBG as well as $\mathrm{HbA}_{1 \mathrm{c}}$. Sobenin et al, ${ }^{39}$ in the 4-week double-blind, placebo-controlled study of 60 type 2 diabetic patients, observed lowering of FBG, $\mathrm{S}$ fructosamine, and S TG levels, with a timed-release garlic preparation given along with oral sulfonylurea derivatives. Similarly, in our study, it was observed that garlic supplemented with metformin showed a greater decrease in FBG, $\mathrm{PPBG}$, and $\mathrm{HbA}_{1 \mathrm{c}}$ levels than did metformin alone.

\section{Lipid profile and BMI}

Obesity is a major recognized risk factor for type 2 diabetes, with its rapidly increasing prevalence resulting in a "diabesity" epidemic. Reductions in weight, TG, and LDL-C, and increase in HDL-C have been recorded in various clinical studies of patients on metformin. ${ }^{40}$ The findings of the present study conclude that there was a significant decrease in S total CH, S TG, and S LDL-C, and a significant increase in S HDL-C (Tables 3 and 4) with metformin alone and with garlic along with metformin; however, the reductions in $\mathrm{S}$ total $\mathrm{CH}, \mathrm{S}$ TG, and S LDL-C and increase in S HDL-C was greater with metformin plus garlic $(P<0.01)$ (Table 5). The reduction in BMI was not significant $(P>0.05)$ in both the groups at the start and at the end of treatment.

Wulfellé et al ${ }^{41}$ conducted a randomized, controlled study for 6 weeks of patients with type 2 diabetes mellitus on metformin and showed a significant decrease $(P<0.05)$ in S CH, S TG, and S LDL-C levels. However, in contrast to the above findings, the decrease in the same parameters was highly significant $(P<0.01)$ in the present study. In another study conducted by $\mathrm{Wu}$ et $\mathrm{al}^{42}$ of 12 patients with type 2 diabetes mellitus on metformin therapy showed a significant decrease $(P<0.05)$ in FBG and $\mathrm{S}$ TG levels and a significant increase in S HDL-C levels. This was in conformity to the present study, where a significant decrease in FBG $(P<0.001)$ and TG $(P<0.05)$ levels and significant increase $(P<0.05)$ in S HDL-C levels were observed. Ashraf et al, ${ }^{38}$ in a 12-week, randomized, single-blind, placebo-controlled study of type 2 diabetes mellitus patients on garlic, showed a highly significant decrease $(P<0.01)$ in total $\mathrm{CH}$ and $\mathrm{S}$ LDL-C levels and a significant increase $(P<0.05)$ in $\mathrm{S}$ HDL-C level. These results are comparable with the present study, where a highly significant decrease $(P<0.01)$ in $\mathrm{S}$ total $\mathrm{CH}, \mathrm{S}$ TG and S LDL-C levels and a highly significant increase $(P<0.01)$ in S HDL-C levels were observed in patients taking garlic along with metformin. In another study conducted by Santen et al, ${ }^{43}$ the lipid-lowering effect of garlic was studied in 40 diabetics with hyperlipidemia, and it showed a highly significant decrease $(P<0.01)$ in $\mathrm{S}$ TG levels and a significant decrease $(P<0.05)$ in total $\mathrm{CH}$ levels. This difference was comparable with the present study, where the decrease in $\mathrm{S} \mathrm{CH}$ and TG levels was significant $(P<0.05)$ in patients taking garlic along with metformin as compared with metformin alone.

\section{Effect on S hs-CRP}

In patients taking only metformin, there was a nonsignificant reduction $(P>0.05)$ in $\mathrm{S}$ hs-CRP levels (Table 3$)$, whereas there was a significant reduction $(P<0.05)$ in $\mathrm{S}$ hs-CRP levels, in type 2 diabetic patients taking metformin supplemented with garlic (Table 4), at the end of study. When $\mathrm{S}$ hs-CRP level was compared between group 1 and group 2, it was observed that there was a significant fall $(P<0.05)$ in $\mathrm{S}$ hs-CRP levels in group 2 (Table 5). Thus, it can be interpreted from present study that metformin treatment does 
not cause statistically significant lowering of CRP levels, but metformin plus garlic treatment significantly decreases the CRP levels. However, long-term studies are required to elucidate the findings of the present study.

CRP reduction with metformin has been widely evaluated in many other studies. Caballero et al, ${ }^{16}$ in their study on the differential effects of metformin on markers of endothelial activation and inflammation in subjects with impaired glucose tolerance, observed that metformin improved the plasma levels of some markers of endothelial activation and coagulation in subjects with impaired glucose tolerance, whereas it had no effect on markers of inflammation. Pradhan et al, ${ }^{44}$ in a study of 500 adults with type 2 diabetes, concluded that treatment with metformin, compared with placebo, did not reduce inflammatory biomarker levels, despite improvement of glucose control. Similarly, Lima et $\mathrm{al}^{14}$ conducted a double-blind, placebo-controlled, prospective, 24-week study in 32 nondiabetic first-degree relatives of patients with type 2 diabetes mellitus who were given extendedrelease metformin, $500 \mathrm{mg}$ once daily. Researchers concluded that there was no change in S hs-CRP level.

\section{SADA activity}

Previous studies ${ }^{11,19}$ have revealed that in type 2 diabetic patients, with increase in $\mathrm{HbA}_{1 \mathrm{c}}$ level, there is an increase in S ADA level. In line with previous work done by other researchers, the SADA level in the present study of type 2 diabetes mellitus patients was significantly higher in both the groups (Tables 3 and 4). However, the fall in S ADA levels was not significant $(P>0.05)$ in patients given metformin only when compared with patients taking metformin plus garlic $(P<0.01)$ (Table 5). Similarly, Koch et $\mathrm{al}^{45}$ reported an inhibition of the enzyme ADA with garlic in in-vitro study. This is in conformity to our findings, where a significant $(P<0.01)$ decrease in S S ADA level was seen in patients taking garlic along with metformin, signifying an ADA-lowering effect of garlic.

\section{Conclusion}

At the end of 12 weeks, it was observed that both metformin and garlic reduced $\mathrm{FBG}, \mathrm{PPBG}$, and $\mathrm{HbA}_{1 \mathrm{c}}$ significantly, but the percentage of change in FBG and PPBG was more substantial with metformin supplemented with garlic than with metformin alone, whereas the difference in mean percentage of change in $\mathrm{HbA}_{1 \mathrm{c}}$ was not significant. Similarly, the beneficial effect of metformin supplemented with garlic on lipid profile parameters, such as the fall in total $\mathrm{CH}$, TG, LDL-C and increase in HDL-C, were greater with metformin supplemented with garlic than with metformin alone. Similarly, the fall in CRP and S ADA levels were seen more notably with metformin supplemented with garlic than with metformin alone. These results lead us to conclude that there is an adjuvant role of garlic, along with other antidiabetic agents, in the treatment and prevention of long-term complications of type 2 diabetes mellitus. However, more clinical trials using garlic in combination with different antidiabetic agents are warranted, to further explore the benefits of garlic in type 2 diabetics.

\section{Acknowledgments}

The authors gratefully acknowledge the support of the Department of Biochemistry and Medicine, Sri Guru Ram Das Institute of Medical Sciences and Research, Amritsar, Punjab, India.

\section{Disclosure}

There were no conflicts of interest in the present study.

\section{References}

1. World Health Organization. Definition, Diagnosis and Classification of Diabetes Mellitus and its Complications. Part 1: Diagnosis and Classification of Diabetes Mellitus. Geneva: World Health Organization; 1999. Available from: http://www.who.int/diabetes/currentpublications/ en/. Accessed December 14, 2012.

2. Ramchandran A, Snehalatha C, Vijay V. Burden of type 2 diabetes and its complications - the Indian scenario. Current Science. 2002;83: 1471-1476.

3. Cowie CC, Eberhardt MS, editors. Diabetes 1996: Vital Statistics. Alexandria: American Diabetes Association; 1996.

4. Davidson MB. Diabetes Mellitus: Diagnosis and Treatment, 3rd ed. New York: Churchill Livingstone; 1991.

5. Stratton IM, Adler AI, Neil HA, et al. Association of glycaemia with macrovascular and microvascular complications of type 2 diabetes (UKPDS 35): prospective observational study. BMJ. 2000;321(7258): 405-412.

6. Stehouwer CD, Gall MA, Twisk JW, Knudsen E, Emeis JJ, Parving HH. Increased urinary albumin excretion, endothelial dysfunction, and chronic low-grade inflammation in type 2 diabetes: progressive, interrelated, and independently associated with risk of death. Diabetes. 2002;51(4):1157-1165.

7. Lapice E, Maione S, Patti L, et al. Abdominal adiposity is associated with elevated C-reactive protein independent of BMI in healthy nonobese people. Diabetes Care. 2009;32(9):1734-1736.

8. Gabay C, Kushner I. Acute-phase proteins and other systemic responses to inflammation. $N$ Engl J Med. 1999;340(6):448-454.

9. Weisberg SP, McCann D, Desai M, Rosenbaum M, Leibel RL, Ferrante AW Jr. Obesity is associated with macrophage accumulation in adipose tissue. J Clin Invest. 2003;112(12):1796-1808.

10. Duncan BB, Schmidt M, Pankow JS, et al. Low-grade systemic inflammation and the development of type 2 diabetes: the atherosclerosis risk in communities study. Diabetes. 2003;52(7):1799-1805.

11. Prakash MS, Chennaiah S, Murthy YS, Anjaiah E, Rao SA, Suresh C. Altered adenosine deaminase activity in type 2 diabetes mellitus. JIACM. 2006;7:114-117.

12. Kurtul N, Pence S, Akarsu E, Kocoglu H, Aksoy Y, Aksoy H. Adenosine deaminase activity in the serum of type 2 diabetic patients. Acta Medica (Hradec Kralove). 2004;47(1):33-35.

13. De Fronzo RA. Pharmacologic therapy for type 2 diabetes mellitus. Ann Intern Med. 1999;131(4):281-303. 
14. Lima LM, Wiernsperger N, Kraemer-Aguiar LG, Bouskela E. Short-term treatment with metformin improves the cardiovascular risk profile in first-degree relatives of subjects with type 2 diabetes mellitus who have a metabolic syndrome and normal glucose tolerance without changes in C-reactive protein or fibrinogen. Clinics (Sao Paulo). 2009;64(5):415-420.

15. American Diabetes Association. Standards of medical care in diabetes 2011. Diabetes Care. 2011;34 Suppl 1:S11-S61.

16. Caballero AE, Delgado A, Aguilar-Salinas CA, et al. The differential effects of metformin on markers of endothelial activation and inflammation in subjects with impaired glucose tolerance: a placebo-controlled, randomized clinical trial. J Clin Endocrinol Metab. 2004;89(8):3943-3948.

17. Haffner S, Temprosa M, Crandall J, et al; Diabetes Prevention Program Research Group. Intensive lifestyle intervention or metformin on inflammation and coagulation in participants with impaired glucose tolerance. Diabetes. 2005;54(5):1566-1572.

18. [No authors listed]. WHO Expert Committee on Diabetes Mellitus: second report. World Health OrganTech Rep Ser. 1980;646:1-80.

19. Agarwal KC. Therapeutic actions of garlic constituents. Med Res Rev. 1996;16(1):111-124.

20. Yeh YY, Yeh SM. Garlic reduces plasma lipids by inhibiting hepatic cholesterol and triacylglycerol synthesis. Lipids. 1994;29(3):189-193.

21. Melzig MF, Krause E, Franke S. Inhibition of adenosine deaminase activity of aortic endothelial cells by extracts of garlic (Allium sativum L.). Pharmazie. 1995;50(5):359-361.

22. Zeb I, Ahmadi N, Nasir K, et al. Aged garlic extract and coenzyme Q10 have favorable effect on inflammatory markers and coronary atherosclerosis progression: A randomized clinical trial. J Cardiovasc Dis Res. 2012;3(3):185-190.

23. Ide N, Lau BH. Garlic compounds minimize intracellular oxidative stress and inhibit nuclear factor-kappa b activation. J Nutr. 2001; 131(Suppl 3):S1020-S1026.

24. Williams MJ, Sutherland WH, McCormick MP, Yeoman DJ, de Jong SA. Aged garlic extract improves endothelial function in men with coronary artery disease. Phytother Res. 2005;19(4):314-319.

25. Lasuna (capsule) [product information]. The Himalaya Drug Company; 2002. Available from: http://www.himalayahealthcare.com/products/ lasuna.htm\#d. Accessed January 5, 2013.

26. Trinder P. Determination of blood glucose using an oxidase peroxidase system with a non-carcinogenic chromogen. J Clin Pathol. 1969;22(2):158-161.

27. Allain C, Poon LS, Chan CS, Richmond W, Fu PC. Enzymatic determination of total serum cholesterol. Clin Chem. 1974;20(4):470-475.

28. Trinder P. Triglycerides estimation by GPO-PAP method. Ann Clin Biochem. 1996;6:24-27.

29. Burstein M, Scholnick HR, Morfin R. Rapid method for the isolation of lipoproteins from human serum by precipitation with polyanions. J Lipid Res. 1970;11(6):583-595.

30. Bairaktari ET, Seferiadis KI, Elisaf MS. Evaluation of methods for the measurement of low-density lipoprotein cholesterol. J Cardiovasc Pharmacol Therapeut. 2005;10(1):45-54.
31. Mendall MA, Patel P, Ballam L, Strachan D, Northfield TC. C reactive protein and its relation to cardiovascular risk factors: a population based cross sectional study. BMJ. 1996;312(7038):1061-1065.

32. Giusti G, Galanti R. Adenosine deaminase. In: Bergmeyer HU, editor. Methods of Enzymatic Analysis, 2nd ed. New York: Academic Press Inc; 1974;2:1092-1099.

33. Jeppsson J, Kobold U, Barr J, et al; International Federation of Clinical Chemistry and Laboratory Medicine (IFCC). Approved IFCC reference method for the measurement of $\mathrm{HbA}_{1 \mathrm{c}}$ in human blood. Clin Chem $\mathrm{Lab}$ Med. 2002;40(1):78-89.

34. NIH/NHLBI (National Institutes of Health, National Heart, Lung, and Blood Insitute). Clinical Guidelines on the Identification, Evaluation and Treatment of Overweight and Obesity in Adults. Bethesda: National Institutes of Health; 1998. Available from: http:/www.nhlbi.nih.gov/ guidelines/obesity/ob_gdlns.htm. Accessed December 14, 2012.

35. Mannucci E, Monami M, Lamanna C, Adalsteinsson JE. Post-prandial glucose and diabetic complications: systematic review of observational studies. Acta Diabetol. 2012;49(4):307-314.

36. Stumvoll M, Nurjhan N, Perriello G, Dailey G, Gerich JE. Metabolic effects of metformin in non-insulin-dependent diabetes mellitus. $N \mathrm{Engl}$ J Med. 1995;333(9):550-554.

37. DeFronzo RA, Goodman AM. Efficacy of metformin in patients with non-insulin dependent diabetes mellitus. The Multicenter Study Group. N Eng J Med. 1995;333(9):541-549.

38. Ashraf R, Alam Khan R, Ashraf I. Effects of garlic on blood glucose levels and $\mathrm{HbA}_{1 \mathrm{c}}$ in patients with type 2 diabetes mellitus. J Med Plants Res. 2011;5(13):2922-2928.

39. Sobenin IA, Nedosugova LV, Filatova LV, Balabolkin MI, Gorchakova TV, Orekhov AN. Metabolic effects of time-released garlic powder tablets in type 2 diabetes mellitus: the results of double-blinded placebo-controlled study. Acta Diabetol. 2008;45(1):1-6.

40. Robinson AC, Burke J, Robinson S, Johnston GD, Elkeles RS. The effects of metformin on glycemic control and serum lipids in insulintreated NIDDM patients with suboptimal metabolic control. Diabetes Care. 1998;2(5):701-705.

41. Wulffelé MG, Kooy A, de Zeeuw D, Stehouwer CD, Gansevoort RT. The effect of metformin on blood pressure, plasma cholesterol and triglycerides in type 2 diabetes mellitus: a systematic review. J Int Med. 2004;256(1):1-14.

42. Wu MS, Johnston P, Sheu WH, et al. Effect of metformin on carbohydrate and lipoprotein metabolism in NIDDM patients. Diabetes Care. 1990;13(1):1-8

43. Santen RJ, Willin PW 3rd, Fajans SS. Atherosclerosis in diabetes mellitus. Correlations with serum lipid levels, adiposity, and serum insulin level. Arch Intern Med. 1972;130(6):833-843.

44. Pradhan AD, Everett BM, Cook NR, Rifai N, Ridker PM. Effects of initiating insulin and metformin on glycemic control and inflammatory biomarkers among patients with type 2 diabetes: the LANCET randomized trial. JAMA. 2009;302(11):1186-1196.

45. Koch HP, Jäger W, Hysek J, Körpert B. Garlic and onion extracts: in vitro inhibition of adenosine deaminase. Phytother Res. 1992;6(1):50-52.

Diabetes, Metabolic Syndrome and Obesity: Targets and Therapy

Dovepress

\section{Publish your work in this journal}

Diabetes, Metabolic Syndrome and Obesity: Targets and Therapy is an international, peer-reviewed open-access journal committed to the rapid publication of the latest laboratory and clinical findings in the fields of diabetes, metabolic syndrome and obesity research. Original research, review, case reports, hypothesis formation, expert opinion and commentaries are all considered for publication. The manuscript management system is completely online and includes a very quick and fair peer-review system, which is all easy to use. Visit http://www.dovepress.com/testimonials.php to read real quotes from published authors. 